\title{
The Relationship between Free Time Satisfaction and Stress Levels of Elite-Level Student-Wrestlers
}

\author{
Fatih Yasarturk ${ }^{1}$, Hayri Akyüz ${ }^{1}$, Ismail Karatas ${ }^{1}$ and Mutlu Turkmen ${ }^{1,2, *}$ (D) \\ 1 School of Physical Education and Sports, Bartin University, 74110 Bartın, Turkey; \\ fyasarturk@bartin.edu.tr (F.Y.); hakyuz@bartin.edu.tr (H.A.); ikaratas@bartin.edu.tr (I.K.) \\ 2 Turkish Bocce Bowling and Darts Federation, 06420 Ankara, Turkey \\ * Correspondence: mutluturkmen@bartin.edu.tr
}

Received: 22 July 2018; Accepted: 25 August 2018; Published: 31 August 2018

\begin{abstract}
The purpose of this research was to examine the relationship between free time satisfaction and stress levels of elite level student wrestlers according to some demographic factors. The sample of the study consisted of 119 ( 85 male and 34 female) elite level student wrestlers who participated in the Wrestling National Team camp in 2018. As data collection tools, "Personal Information Form", "Stress Scale in Working Life: SSWL", and "Free Time Satisfaction Scale: FTSS" were used. In the analysis of the derived data, $t$-test, Mann-Whitney $\mathrm{U}$, and Kruskal-Wallis were used, and Pearson Correlation test was applied to examine relations between study variables. There was no significant difference in the $t$-test results according to the "gender" variable $(p>0.05)$. There was a meaningful, low-level negative correlation between the "age" variable and social, aesthetic, sub-dimensions of stress scale. As a result, this study found that participants' free time satisfaction levels were related to age; and stress levels were related to age, sport year, national team year, and income level.
\end{abstract}

Keywords: elite-level student-wrestlers; free time satisfaction; stress

\section{Introduction}

Today, free time or recreational activities are the greatest entertainment, happiness, and saturation point of all individuals. Such activities will move individuals away from stress, anxiety, and unhappiness. Thus, it can be said that the quality of life is increased. Quality of life is closely related to our health status. It is influenced by our behavior regarding food style, sports activity, workplace, the way we can or cannot relax, or the way we know how to choose or distinguish between right or wrong [1,2]. Moreover, recreational activities will contribute to the achievement of their work or other physical activities.

Specific and intense training is central to performance enhancement and subsequent success in elite sports. Athletes aspire to be physically as well prepared as possible to compete in the highest levels of competition. Coaches and athletes, therefore, are constantly searching for new training methods and strategies to gain a competitive edge [3].

The concept of stress became an important part of today's modern life. Stress, a term that is frequently used in daily life, is also a factor that affects all aspects of human life [4]. According to Aydin (2017), stress is expressed as one of the most important factors that affect the well-being of the individual negatively and disturbs their health [5]. In another definition, stress can be defined as an experience in which people perceive situational demands that exceed their coping resources [6,7].

Free time is a concept that has been defined in various ways. Free time was briefly defined as the time spent away from work, sleep, and necessary activities by Roberts, and the activities done in this time were named free time activities [8]. 
Schermerhorn et al. defined satisfaction as an emotional reaction of the individual against physical and social conditions, as well as against daily life activities and as the degree to which the expectations in the individual's psychological contract are satisfied [9]. Free time satisfaction occurs if the leisure participation meets one's expectations [10].

Free time satisfaction is the degree to which the expectations of the individual from the activities he actively or passively participated in voluntarily without any external pressures in order to gain new skills and have feelings of health, entertainment, content, renewal, and happiness with health, social, cultural, sportive, or artistic expectations [11]. In another definition, free time satisfaction can be defined as positive perceptions or feelings formed or gained by an individual engaging in leisure activities and choices [12].

These developments in the sport branches and reaching the upper limits of the competitions make it possible to increase the quantity and quality of the athletes at the elite level. The secret of reaching success requires psychological and sociological development, as well as physical development. Therefore, even if one of the effective causes is deficiency or insufficiency, the performance of the individual will decrease [13].

Elite-level athletes spend most of their time in the day with both physical and mental training. Especially because wrestling requires physical performance, the level of stress generated during training or competition is an important factor in achieving success. Controlling the level of stress of elite-level wrestlers and satisfying their leisure time activities will increase the likelihood of success in sports competitions. Therefore, in the scope of this research, the determination of stress and the free-time satisfaction levels of elite level wrestlers will shed light on the determinants of the factors affecting performance and support future studies.

In light of the above information, the purpose of this study was to examine the relationship between elite level wrestlers' free time satisfaction and stress levels according to some demographic factors. As this is the first attempt to explore the relationship between free time satisfaction and stress levels of elite wrestlers, the findings of this study will inspire the coaches of Turkish national wrestling teams to take some precautions accordingly.

\section{Materials and Methods}

In the research, "Descriptive (Figurative) and Relational Search Model" was used in accordance with the above-mentioned research purposes.

\subsection{Universe and Sampling}

Research universe is composed of Turkish national level student wrestlers. The sample of the study is composed of 119 ( 85 male and 34 female) elite-level wrestlers who participated to the Turkish Wrestling National Team Camp in 2018. The data was derived from the beginning of February until the end of March in 2018 with the permission of the coaches. All the athletes participated in the study voluntarily without any exceptions.

\subsection{Data Collection Tools}

Personal Information Form, Free Time Satisfaction Scale, and Stress Scale were used as data collection tools in the study. At the beginning of the camp period, the researchers visited the camp and attended the opening meeting with the coaches and managers briefing all the athletes about the purpose of the study and the questionnaire forms. The forms were delivered to the athletes and recollected at the end of the camp period.

\subsubsection{Personal Information Form}

The personal information form consists of variables such as gender; age; income level; marital status; educational status; sport year, which shows the total years of wrestling practice; 
national team year, which shows the duration of the years on the national team; wrestling style; nationality grade; and free time-period.

\subsubsection{Free Time Satisfaction Scale}

The Free Time Satisfaction Scale was developed by Beard \& Ragheb (1980) and Turkish adaptation was made by Gökçe \& Orhan (2011) [12,14]. FTSS is composed of six sub-dimensions: psychological, educational, social, relaxation, physiological, and esthetic. The "Free Time Satisfaction Scale", consisting of a total of 24 items, was rated on a 5-point Likert type scale, and expressions were scored as " $1=$ Almost Not True", " $2=$ Rarely True", " 3 = Sometimes True", " $4=$ Many Times True", and " $5=$ Almost Always True".

\subsubsection{Stress Scale}

The "Stress Scale" developed by Odabas1 (2006) consists of 10 expressions to determine the stress level [15]. These expressions are prepared according to the Likert scale of 5 and are scored as "never $=1$, rarely $=2$, occasional $=3$, frequent $=4$, and very frequently $=5^{\prime \prime}[16]$.

\subsection{Analysis of Data}

SPSS 23.0 (Statistical Package for Social Sciences) package program was used in the analysis of the data. In the descriptive data analysis, frequency, percentage, mean, and standard deviation analyzes were used. In the analysis of the data, according to the demographic characteristics of the participants, $t$-test, Mann-Whitney $\mathrm{U}$, and Kruskal-Wallis used to investigate the differences between free time satisfaction and stress levels, Pearson Correlation test was applied to examine relations between variables. In the statistical analysis of the data $\alpha=0.05$, significance level was taken into consideration.

It can be said that these calculated values are within statistically acceptable limits and are highly reliable [17]. Alfa Reliability Coefficients of both scales are presented in Table 1 below.

Table 1. Free Time Satisfaction Scale and Stress Scale Alfa Reliability Coefficients.

\begin{tabular}{ccc}
\hline Dimensions & $\mathbf{N}$ & Cronbach's Alpha Coefficient \\
\hline Psychological & 4 items & 0.789 \\
Educational & 4 items & 0.736 \\
Social & 4 items & 0.735 \\
Relaxation & 4 items & 0.680 \\
Physiological & 4 items & 0.713 \\
Esthetic & 4 items & 0.770 \\
Free Time Satisfaction Scale & 20 items & 0.918 \\
Stress Scale & 10 items & 0.860 \\
\hline
\end{tabular}

$\mathrm{N}$-number of subjects.

\section{Results}

As presented in Table 2, $28.6 \%$ of the participants are female, $71.4 \%$ are male wrestlers, and 79 of the wrestlers are freestyle 40 wrestlers in Greco-Roman style. $11.8 \%$ of the participants are in secondary education, $79.8 \%$ are in university, and $8.4 \%$ are in post-graduate education level. According to the marital status variable, 26 of the participants are single, and 93 are married. $32.8 \%$ of participants are composed of "A National", $43.7 \%$ of "B National", and 23.5\% of "C National" wrestlers, which shows the level of national team participation. A refers to seniors participating in continental and world championships or more important multi-sport organizations; B refers to juniors/espoirs, and $\mathrm{C}$ to the athletes participating in international level tournaments. 
Table 2. Frequency and Percentage Distributions of Participants.

\begin{tabular}{cccc}
\hline Variables & Groups & N & $\%$ \\
\hline \multirow{2}{*}{ Gender } & Female & 34 & 28.6 \\
& Male & 85 & 71.4 \\
\hline \multirow{2}{*}{ Wrestling Style } & Free & 79 & 66.4 \\
& Greco-Roman & 40 & 33.6 \\
\hline \multirow{2}{*}{ Education Status } & Secondary & 14 & 11.8 \\
& University & 95 & 79.8 \\
& Postgraduate & 10 & 8.4 \\
\hline \multirow{2}{*}{ Marital Status } & Married & 26 & 21.8 \\
& Single & 93 & 78.2 \\
\hline \multirow{2}{*}{ National Degree } & A National & 39 & 32.8 \\
& B National & 52 & 43.7 \\
& C National & 28 & 23.5 \\
\hline Total & & 119 & 100.0 \\
\hline
\end{tabular}

According to Table 3, the average age of participants is 24.53; average of sports year 11.90; average of National Team Year 6.78; average of income level $3309.70 \mathrm{TL}$; average of free time $5.54 \mathrm{~h}$.

Table 3. Score Averages and Standard Deviation Values of Participants According to Variables.

\begin{tabular}{cccc}
\hline Variables & $\mathbf{N}$ & $\overline{\mathbf{X}}$ & SD \\
\hline Age & 119 & 24.53 & 3.83 \\
Sports Year & 119 & 11.90 & 4.77 \\
National Team Year & 119 & 6.78 & 4.23 \\
Income Level & 119 & 3309.70 & 2252.18 \\
Free Time & 119 & 5.54 & 2.27 \\
\hline N-number of subjects; $\overline{\mathbf{X}}-$ mean; SD &
\end{tabular}

According to the Table 4, there was no statistically significant difference in the $t$-test results according to the "gender" variable $(p>0.05)$.

Table 4. Two Independent Sample $t$-Test Results Towards Participants' Gender Variables.

\begin{tabular}{|c|c|c|c|c|c|c|c|}
\hline Dimensions & Gender & $\mathbf{N}$ & $\bar{x}$ & SD & $t$ & df & $p$ \\
\hline \multirow{2}{*}{ Psychological } & Male & 85 & 3.3059 & 0.82949 & \multirow{2}{*}{-0.736} & \multirow{2}{*}{117} & \multirow{2}{*}{0.540} \\
\hline & Female & 34 & 3.4338 & 0.92177 & & & \\
\hline \multirow{2}{*}{ Educational } & Male & 85 & 3.5235 & 0.68750 & \multirow{2}{*}{-0.551} & \multirow{2}{*}{117} & \multirow{2}{*}{0.649} \\
\hline & Female & 34 & 3.6029 & 0.76405 & & & \\
\hline \multirow{2}{*}{ Social } & Male & 85 & 3.5824 & 0.71171 & \multirow{2}{*}{-0339} & \multirow[b]{2}{*}{117} & \multirow{2}{*}{0.191} \\
\hline & Female & 34 & 3.6324 & 0.76682 & & & \\
\hline \multirow{2}{*}{ Relaxation } & Male & 85 & 3.7676 & 0.67897 & \multirow{2}{*}{0.175} & \multirow{2}{*}{117} & \multirow{2}{*}{0.263} \\
\hline & Female & 34 & 3.7426 & 0.76744 & & & \\
\hline \multirow{2}{*}{ Physiological } & Male & 85 & 3.3824 & 0.75058 & \multirow{2}{*}{-1.874} & \multirow{2}{*}{117} & \multirow{2}{*}{0.939} \\
\hline & Female & 34 & 3.6691 & 0.76307 & & & \\
\hline \multirow{2}{*}{ Aesthetic } & Male & 85 & 3.6706 & 0.77461 & \multirow{2}{*}{-0.843} & \multirow{2}{*}{117} & \multirow{2}{*}{0.951} \\
\hline & Female & 34 & 3.8015 & 0.74054 & & & \\
\hline \multirow{2}{*}{ FTSS } & Male & 85 & 3.5387 & 0.55993 & \multirow{2}{*}{-0.901} & \multirow{2}{*}{117} & \multirow{2}{*}{0.054} \\
\hline & Female & 34 & 3.6471 & 0.66803 & & & \\
\hline \multirow{2}{*}{ SSWL } & Male & 85 & 3.1235 & 0.59575 & \multirow{2}{*}{6.658} & \multirow{2}{*}{117} & \multirow{2}{*}{0.561} \\
\hline & Female & 34 & 2.3000 & 0.64338 & & & \\
\hline
\end{tabular}

$\mathrm{N}-$ number of subjects; $\overline{\mathbf{X}}$-mean; SD—standard deviation; $t$-Student test values; $p$-level of probability; df-degree of freedom. 
According to the Table 5, as a result of the correlation analysis made to show the relation between "age" variable and the FTSS subscales and Stress scale, FTSS "social" $(\mathrm{r}=-0.192 *, p<0.05)$ and "esthetic" ( $\left.\mathrm{r}=-0.253^{*}, p<0.05\right)$ sub-factors and FTSS total averages $(\mathrm{r}=-0.204 *, p<0.05)$ were found to have a significant negative correlation at low level. Stress Scale total points $\left(\mathrm{r}=0.345^{*}, p<0.05\right)$ were found to have a statistically significant, moderate, positive relationship.

Table 5. Free Time Satisfaction Scale and Stress Scale Correlation Test Results According to the Age Variables of Participants.

\begin{tabular}{ccccccccc}
\hline Variable & Psych. & Educ. & Soc. & Relax. & Phys. & Esth. & FTSS & SSWL \\
\hline Age & -0.136 & -0.173 & $-0.192^{*}$ & -0.063 & -0.141 & $-0.253 *$ & $-0.204^{*}$ & $0.345^{*}$ \\
\hline \multicolumn{8}{c}{$p<0.05}$. \\
\hline \multicolumn{1}{c}{${ }^{*} p$}
\end{tabular}

According to the Table 6, as a result of the correlation analysis made to show the relation between "sport year" and FTSS sub-factors and Stress Scale, the stress scale total scores $(\mathrm{r}=0.350 *, p<0.05)$ was found to have a statistically significant, moderate, positive relationship.

Table 6. Free Time Satisfaction Scale and Stress Scale Correlation Test Results According to the Sports Year Variables of Participants.

\begin{tabular}{ccccccccc}
\hline Variable & Psych. & Educ. & Soc. & Relax. & Phys. & Esth. & FTSS & SSWL \\
\hline Sports Year & -0.099 & -0.057 & -0.116 & 0.043 & -0.087 & -0.167 & -0.105 & $0.350 *$ \\
\hline \multicolumn{8}{c}{$*<0.05}$.
\end{tabular}

According to Table 7, as a result of the correlation analysis made to show the relation between "National Team Year" and FTSS sub-factors and Stress Scale, the stress scale total scores $(r=0.323 * *$, $p<0.05)$ were found to have a statistically significant, low-level, positive relationship.

Table 7. Free Time Satisfaction Scale and Stress Scale Correlation Test Results According to the National Team Year Variables of Participants.

\begin{tabular}{ccccccccc}
\hline Variable & Psych. & Educ. & Soc. & Relax. & Phys. & Esth. & FTSS & SSWL \\
\hline National Team Year & -0.100 & -0.016 & -0.102 & 0.102 & -0.065 & -0.098 & -0.063 & $0.323^{*}$ \\
\hline \multicolumn{8}{c}{${ }^{*} p<0.05}$.
\end{tabular}

According to the Table 8, as a result of the correlation analysis made to show the relation between "income level" and FTSS sub-factors and Stress Scale, the stress scale total scores $\left(\mathrm{r}=0.328^{* *}, p<0.05\right)$ were found to have a statistically significant, low-level, positive relationship.

Table 8. Free Time Satisfaction Scale and Stress Scale Correlation Test Results According to the Income Level Variables of Participants.

\begin{tabular}{ccccccccc}
\hline Variable & Psych. & Educ. & Soc. & Relax. & Phys. & Esth. & FTSS & SSWL \\
\hline Income Level & 0.005 & -0.013 & -0.018 & -0.017 & -0.099 & 0.020 & -0.025 & $0.328^{*}$ \\
\hline \multicolumn{8}{c}{$p<0.05}$.
\end{tabular}

According to the Table 9, no statistically significant correlation was found as a result of correlation analysis $(p>0.05)$.

Table 9. Free Time Satisfaction Scale and Stress Scale Correlation Test Results According to the Free Time Variables of Participants.

\begin{tabular}{ccccccccc}
\hline Variable & Psych. & Educ. & Soc. & Relax. & Phys. & Esth. & FTSS & SSWL \\
\hline Free Time & 0.121 & 0.156 & 0.158 & 0.049 & 0.027 & 0.101 & 0.130 & 0.139 \\
\hline
\end{tabular}


According to the Table 10, when the participants' free time satisfaction and stress point averages were examined in terms of wrestling style variables, a statistically significant difference was found in free time satisfaction scale "educational" sub-dimension and the stress scale total scores $(p<0.05)$. When the mean values were examined, it was seen that freestyle wrestlers have higher average values than Greco-Roman-style wrestlers in terms of the "educational" sub-dimension of the free time satisfaction scale; Greco-Roman-style wrestlers have higher average value than freestyle wrestlers in terms of stress scale total scores.

Table 10. Two Independent Sample $t$-Test Results Towards Participants' Wrestling Style Variables.

\begin{tabular}{|c|c|c|c|c|c|c|c|}
\hline Dimensions & Wrestling Style & $\mathbf{N}$ & $\bar{X}$ & SD & $t$ & df & $p$ \\
\hline \multirow{2}{*}{ Psychological } & Free & 79 & 3.2880 & 0.83502 & \multirow{2}{*}{-0.976} & \multirow{2}{*}{117} & \multirow{2}{*}{0.517} \\
\hline & Greco-Roman & 40 & 3.4500 & 0.89371 & & & \\
\hline \multirow[b]{2}{*}{ Educational } & Free & 79 & 3.5696 & 0.76265 & \multirow[b]{2}{*}{0.505} & \multirow[b]{2}{*}{117} & \multirow[b]{2}{*}{0.044} \\
\hline & Greco-Roman & 40 & 3.5000 & 0.59107 & & & \\
\hline \multirow{2}{*}{ Social } & Free & 79 & 3.5570 & 0.75527 & \multirow{2}{*}{-0.838} & \multirow{2}{*}{117} & \multirow{2}{*}{0.191} \\
\hline & Greco-Roman & 40 & 3.6750 & 0.66313 & & & \\
\hline \multirow[b]{2}{*}{ Relaxation } & Free & 79 & 3.7184 & 0.73092 & \multirow{2}{*}{-0.920} & \multirow{2}{*}{117} & \multirow{2}{*}{0.084} \\
\hline & Greco-Roman & 40 & 3.8438 & 0.64223 & & & \\
\hline \multirow{2}{*}{ Physiological } & Free & 79 & 3.4968 & 0.76113 & \multirow{2}{*}{0.653} & \multirow{2}{*}{117} & \multirow{2}{*}{0.574} \\
\hline & Greco-Roman & 40 & 3.4000 & 0.76962 & & & \\
\hline \multirow{2}{*}{ Esthetic } & Free & 79 & 3.7310 & 0.83087 & \multirow{2}{*}{0.460} & \multirow[b]{2}{*}{117} & \multirow{2}{*}{0.103} \\
\hline & Greco-Roman & 40 & 3.6625 & 0.61901 & & & \\
\hline \multirow{2}{*}{ FTSS } & Free & 79 & 3.5601 & 0.63397 & \multirow{2}{*}{-0.246} & \multirow{2}{*}{117} & \multirow{2}{*}{0.080} \\
\hline & Greco-Roman & 40 & 3.5885 & 0.50577 & & & \\
\hline \multirow{2}{*}{ SSWL } & Free & 79 & 2.7873 & 0.74513 & \multirow{2}{*}{-2.205} & \multirow{2}{*}{117} & \multirow{2}{*}{0.031} \\
\hline & Greco-Roman & 40 & 3.0875 & 0.60434 & & & \\
\hline
\end{tabular}

$\mathrm{N}-$ number of subjects; $\overline{\mathbf{X}}$-mean; SD—standard deviation; $t$-Student test values; $p$-level of probability; $\mathrm{df}$ - degree of freedom.

According to the Table 11, there was no statistically significant difference in the Mann-Whitney U results according to the "marital status" variable $(p>0.05)$.

Table 11. Mann-Whitney U Test Results of Free Time Satisfaction Scale and Stress Scale Point Scores According to Participants' Marital Status Variable.

\begin{tabular}{|c|c|c|c|c|c|c|}
\hline Dimensions & Groups & $\mathbf{N}$ & Average Rank & Rank Sum & $\mathbf{U}$ & $p$ \\
\hline \multirow{2}{*}{ Psychological } & Married & 26 & 55.79 & 1450.50 & \multirow{2}{*}{1099.5} & \multirow{2}{*}{0.479} \\
\hline & Single & 93 & 61.18 & 5689.50 & & \\
\hline \multirow{2}{*}{ Educational } & Married & 26 & 53.94 & 1402.50 & \multirow{2}{*}{1051} & \multirow{2}{*}{0.308} \\
\hline & Single & 93 & 61.69 & 5737.50 & & \\
\hline \multirow{2}{*}{ Social } & Married & 26 & 52.56 & 1366.50 & \multirow{2}{*}{1015.5} & \multirow{2}{*}{0.210} \\
\hline & Single & 93 & 62.08 & 5773.50 & & \\
\hline \multirow{2}{*}{ Relaxation } & Married & 26 & 67.71 & 1760.50 & \multirow{2}{*}{1008.5} & \multirow[b]{2}{*}{0.194} \\
\hline & Single & 93 & 57.84 & 5379.50 & & \\
\hline \multirow{2}{*}{ Physiological } & Married & 26 & 60.94 & 1584.50 & \multirow{2}{*}{1184.5} & \multirow{2}{*}{0.874} \\
\hline & Single & 93 & 59.74 & 5555.50 & & \\
\hline \multirow{2}{*}{ Esthetic } & Married & 26 & 55.60 & 1445.50 & \multirow{2}{*}{1094.5} & \multirow{2}{*}{0.457} \\
\hline & Single & 93 & 61.23 & 5694.50 & & \\
\hline \multirow{2}{*}{ FTSS } & Married & 26 & 57.17 & 1486.50 & \multirow{2}{*}{1135.5} & \multirow{2}{*}{0.636} \\
\hline & Single & 93 & 60.79 & 5653.50 & & \\
\hline \multirow{2}{*}{ SSWL } & Married & 26 & 62.12 & 1615.00 & \multirow{2}{*}{1154} & \multirow{2}{*}{0.723} \\
\hline & Single & 93 & 59.41 & 5525.00 & & \\
\hline
\end{tabular}

$\mathrm{N}$-number of subjects; $\mathrm{U}$-the Mann-Whitney test value; $p$-level of probability. 
According to Table 12, there was no statistically significant difference in the Kruskal-Wallis results according to the "national degree" variable $(p>0.05)$.

Table 12. Kruskal-Wallis Test Results of Free Time Satisfaction Scale and Stress Scale Point Scores According to Participants' National Degree Variable.

\begin{tabular}{|c|c|c|c|c|c|c|}
\hline Dimensions & Groups & $\mathbf{N}$ & Average Rank & df & $X^{2}$ & $p$ \\
\hline \multirow{3}{*}{ Psychological } & A National & 39 & 64.63 & \multirow{3}{*}{2} & \multirow{3}{*}{2.279} & \multirow{3}{*}{0.320} \\
\hline & B National & 52 & 54.63 & & & \\
\hline & C National & 28 & 63.54 & & & \\
\hline \multirow{3}{*}{ Educational } & A National & 39 & 63.68 & \multirow{3}{*}{2} & \multirow{3}{*}{0.684} & \multirow{3}{*}{0.710} \\
\hline & B National & 52 & 57.85 & & & \\
\hline & C National & 28 & 58.88 & & & \\
\hline \multirow{3}{*}{ Social } & A National & 39 & 62.06 & \multirow{3}{*}{2} & \multirow{3}{*}{5.404} & \multirow{3}{*}{0.067} \\
\hline & B National & 52 & 52.60 & & & \\
\hline & C National & 28 & 70.88 & & & \\
\hline \multirow{3}{*}{ Relaxation } & A National & 39 & 63.67 & \multirow{3}{*}{2} & \multirow{3}{*}{4.348} & \multirow{3}{*}{0.114} \\
\hline & B National & 52 & 52.82 & & & \\
\hline & C National & 28 & 68.23 & & & \\
\hline \multirow{3}{*}{ Physiological } & A National & 39 & 64.44 & \multirow{3}{*}{2} & \multirow{3}{*}{3.101} & \multirow{3}{*}{0.212} \\
\hline & B National & 52 & 53.73 & & & \\
\hline & C National & 28 & 65.46 & & & \\
\hline \multirow{3}{*}{ Esthetic } & A National & 39 & 63.68 & \multirow{3}{*}{2} & \multirow{3}{*}{1.375} & \multirow{3}{*}{0.503} \\
\hline & B National & 52 & 55.86 & & & \\
\hline & C National & 28 & 62.57 & & & \\
\hline \multirow{3}{*}{ FTSS } & A National & 39 & 63.45 & \multirow{3}{*}{2} & \multirow{3}{*}{3.189} & \multirow{3}{*}{0.203} \\
\hline & B National & 52 & 53.75 & & & \\
\hline & C National & 28 & 66.80 & & & \\
\hline \multirow{3}{*}{ SSWL } & A National & 39 & 57.56 & \multirow{3}{*}{2} & \multirow{3}{*}{1.681} & \multirow{3}{*}{0.431} \\
\hline & B National & 52 & 64.52 & & & \\
\hline & C National & 28 & 55.00 & & & \\
\hline
\end{tabular}

According to the Table 13, there was no statistically significant difference in the Kruskal-Wallis results according to the "education status" variable $(p>0.05)$.

Table 13. Kruskal-Wallis Test Results of Free Time Satisfaction Scale and Stress Scale Point Scores According to Participants' Education Status Variable.

\begin{tabular}{ccccccc}
\hline Dimensions & Groups & $\mathbf{N}$ & Average Rank & df & $\mathbf{X}^{\mathbf{2}}$ & $\boldsymbol{p}$ \\
\hline \multirow{3}{*}{ Psychological } & Secondary & 14 & 55.75 & & & \\
& University & 95 & 60.47 & 2 & 0.250 & 0.882 \\
& Postgraduate & 10 & 61.45 & & & \\
\hline \multirow{3}{*}{ Educational } & Secondary & 14 & 51.32 & & & \\
& University & 95 & 62.14 & 2 & 1.830 & 0.400 \\
& Postgraduate & 10 & 51.85 & & & \\
\hline \multirow{3}{*}{ Social } & Secondary & 14 & 55.29 & & & \\
& University & 95 & 61.38 & 2 & 0.787 & 0.675 \\
& Postgraduate & 10 & 53.45 & & & \\
\hline & Secondary & 14 & 53.71 & & & \\
& University & 95 & 62.70 & 2 & 3.479 & 0.176 \\
& Postgraduate & 10 & 43.15 & & & \\
\hline
\end{tabular}


Table 13. Cont.

\begin{tabular}{ccccccc}
\hline Dimensions & Groups & N & Average Rank & df & $\mathbf{X}^{\mathbf{2}}$ & $\boldsymbol{p}$ \\
\hline \multirow{3}{*}{ Physiological } & Secondary & 14 & 54.79 & & & \\
& University & 95 & 59.51 & 2 & 1.557 & 0.459 \\
& Postgraduate & 10 & 71.95 & & & \\
\hline \multirow{3}{*}{ Esthetic } & Secondary & 14 & 58.43 & & & \\
& University & 95 & 60.35 & 2 & 0.050 & 0.975 \\
& Postgraduate & 10 & 58.90 & & & \\
\hline \multirow{3}{*}{ FTSS } & Secondary & 14 & 52.36 & & & \\
& University & 95 & 61.58 & 2 & 1.048 & 0.592 \\
& Postgraduate & 10 & 55.65 & & & \\
\hline \multirow{3}{*}{ SSWL } & Secondary & 14 & 53.57 & & & \\
& University & 95 & 62.22 & 2 & 2.106 & 0.349 \\
& Postgraduate & 10 & 47.95 & & & \\
\hline N-number of subjects; $X^{2}$-Kruskal-Wallis Test value; df-degree of freedom; $p$-level of probability.
\end{tabular}

According to the Table 14, as a result of the correlation analysis made to show the relation between "Stress Scale and FTSS", there was a statistically significant low level negative correlation between SSWL and FTSS $\left(\mathrm{r}=-0.262^{* *}, p<0.05\right)$, "educational" $\left(\mathrm{r}=-0.241^{* *}, p<0.05\right)$, "social" $(\mathrm{r}=-0.212 *$, $p<0.05)$, "physiological" ( $\left.\mathrm{r}=-0.247^{* *}, p<0.05\right)$, and "esthetic" $\left(\mathrm{r}=-0.187^{*}, p<0.05\right)$ sub-factors were found to have a significant negative correlation at low level.

Table 14. Correlation Test Results between Free Time Satisfaction Scale and Stress Scale.

\begin{tabular}{|c|c|c|c|c|c|c|c|c|}
\hline Dimensions & Psych. & Educ. & Soc. & Relax. & Phys. & Esth. & FTSS & SSWL \\
\hline Psych. & 1 & & & & & & & \\
\hline Educ. & $0.613^{* *}$ & 1 & & & & & & \\
\hline Soc. & $0.625^{* *}$ & $0.639 * *$ & 1 & & & & & \\
\hline Relax. & $0.454^{* *}$ & 0.423 ** & $0.611^{* *}$ & 1 & & & & \\
\hline Phys. & $0.582 * *$ & $0.521^{* *}$ & $0.521 * *$ & $0.474^{* *}$ & 1 & & & \\
\hline Esth. & $0.537^{* *}$ & $0.546^{* *}$ & $0.559 * *$ & $0.534^{* *}$ & $0.474^{* *}$ & 1 & & \\
\hline FTSS & $0.821^{* *}$ & $0.790 * *$ & $0.835^{* *}$ & $0.732 * *$ & $0.760 * *$ & $0.775^{* *}$ & 1 & \\
\hline SSWL & -0.173 & $-0.241^{* *}$ & $-0.212^{*}$ & -0.180 & $-0.247^{* *}$ & $-0.187^{*}$ & $-0.262 *$ & 1 \\
\hline
\end{tabular}

\section{Discussions}

There was no statistically significant difference in the $t$-test results according to the "gender" variable in terms of FTSS and SSWL. Eraslan and Dunn (2015) did not find any significant difference according to the sex variable in their study entitled "Analysis of Stress Levels of School of Physical Education and Sports Students According to Various Variables" [18], which supports findings of this research. In the research carried out by Olff et al. (2007), it was indicated that stress level differs according to gender variable in the athletes, which contradicts the findings of this research [19]. Sonmezoglu et al. (2014) found that female attendees had higher levels of leisure satisfaction when compared to the males [20]. Therefore, some findings in previous research coincide with our research, but some do not.

According to correlation analysis between "age" variable and the FTSS subscales and Stress scale, FTSS "social" and "esthetic" sub-factors and FTSS total averages were found to have a significant low-level negative correlation. Akgul et al. (2014) indicated that there was no significant differences according to the age variables in the sub-scales of FTSS in their study [21]. Muzindutsi (2015) found that there was a positive low-level relation in terms of FTSS total scores and subscales [22]. These findings also do not coincide with the findings of this research. 
As a result of the correlation analysis between sport year, national team year, income level, and FTSS sub-factors and Stress Scale, a statistically significant positive relationship was found in the Stress Scale. Ayyildiz and Gokyurek (2016) found that as the level of income increased, the level of free time satisfaction increased in the study of individuals participating in recreational dance activities [23]. Akgul et al. (2014) found that a significant difference has been revealed between Leisure Satisfaction Scale's sub-scale of education and esthetic according to perceived income in their study [21]. They indicated that those who had higher perceived income had higher free-time satisfaction levels in terms of education and esthetics sub-dimension. All these findings support our findings. On the contrary, no statistically significant relation was found in terms of free-time variable.

When the participants' free time satisfaction and stress point averages were examined in terms of wrestling style variable, a statistically significant difference was found in free-time satisfaction scale "educational" sub-dimension and the stress scale total scores. When the mean values were examined, it was seen that freestyle wrestlers have higher average values than Greco-Roman-style wrestlers in terms of the "educational" sub-dimension of the free time satisfaction scale. Greco-Roman-style wrestlers have higher average value than freestyle wrestlers in terms of stress-scale total scores.

There was no statistically significant difference in the Mann-Whitney $U$ results according to the "marital status" variable. Ayyildiz and Gokyurek (2016) found that there was a meaningful relationship between the marital status variable and all the subdimensions [23]. This finding does not coincide with the findings of this research.

There was no statistically significant difference in the Kruskal-Wallis results according to the "national degree" and "education status" variables. Ayyildiz et al. (2016) found that there were no significant differences in FTSS total scores according to the national degree and education status [24]. This finding supports our findings.

As a result of the correlation analysis made to show the relation between "Stress Scale and FTSS", there was a statistically significant, low-level, negative correlation between SSWL and FTSS; "educational", "social", "physiological", and "esthetic" sub-factors were found to have a significant negative correlation with participants' stress levels.

This study was conducted on the elite athletes, all of whom are students. Being a student may have an additional effect on the stress levels, and student-athletes may have less time compared to non-student athletes. Therefore, this study is limited, with student wrestlers as the limitation, and future studies should focus on non-student athletes.

This study is original, as it has it is the first to focus on the relation of stress and free-time satisfaction of elite level wrestlers. As wrestling is one of the most popular sports in Turkey, it is important to underline various socio-psychological factors affecting the athletes, which will guide their coaches accordingly.

\section{Conclusions}

There was no significant difference between elite-level athletes according to the gender variable. Similar sports performances of national athletes show similarities in their free-time satisfaction and stress levels.

Age variables are important among wrestlers, as well as in all branches, because as age increases, there will be a decline in performance after a certain period of time. In line with this result, the experience of elite-level wrestlers will increase as age increases. In addition, increases in the age variables will increase the success of elite-level athletes, because athletes will workout regularly, will develop their level with competitions, and will win a medal or prize eventually. Therefore, it can be said that there is a difference in the match performance of the athlete, as the age progression will facilitate the achievement. There will be changes in the stress level, as well as in the age of the athletes.

As the elite level wrestlers are in an intensive camp, training, and competition period, they do not have enough time to participate in leisure activities. Hence, it can be said that they do not have sufficient free-time satisfaction. In addition, the region may be an effective factor, or it may cause 
some problems regarding reaching full saturation in such activities. In particular, the fact that the years of sports and nationality are high plays a role in the intensification of training and competition. Stress levels of athletes and sport and National Team Year variables were found to be negatively related. For this reason, it can be said that elite level wrestlers reach the full peak of sports life. As a result, we can say that the rise of sport and nationality has created a desire for success in elite-level wrestlers and triggers the increase of stress.

There was no significant relationship and difference between free time and wrestling style variables. However, elite level wrestlers have been found to have less free time. This situation can increase their stress levels. The marital status and national level play an important role in elite-level athletes. However, the intensity of sports life cannot be ignored in both variables. There is no significant difference in these findings between the two variables.

It is foreseen that elite-level wrestlers will be different in their personal and social lives when they are single or married. However, as the participants are all elite-level athletes, they all have to attend a very intensive training and competition programs. As a result, the participants' free time satisfaction levels are closer to each other according to the marital status variable as their social time is very limited. When educational status is examined, especially in the elite level wrestlers, sport year is an important factor. However, the educational situation is a determining factor in the everyday life of elite-level wrestlers and in academic platforms. We can say that free time satisfaction and stress levels are not effective in terms of education variables due to the similar levels of the elite-level athletes.

When scores of free time satisfaction and stress scale were examined, a low, negative correlation was found between the scales. According to this result, as the level of elite-level wrestlers' satisfaction from free-time activities increases, the stress levels in the sporting events are reduced, because participants who are active in leisure-time activities are involved in physical activity, sports activities, and relaxation activities. Individuals who are involved in such activities will have fun and experience relaxation, happiness, satisfaction, and a high quality of life. We can say that as the level of free-time satisfaction of participants increases, stress levels decrease. In this case, we can say that athletes will avoid anxiety, depression, and stress events. As the findings of study accurately conveyed that free-time satisfaction is an important factor for preventing stress among the athletes, this study will inspire coaches, managers of national teams, and instructors to design their camp periods so they include sufficient free-time activities.

It is important to note that this research is limited to participants who are students and elite-level wrestlers. Therefore, being a student and an elite-level athlete at the same time may create extra stress for the athletes. Therefore, similar research should also be conducted on other wrestling groups who do not have regular education responsibilities to obtain a more comprehensive understanding of the subject.

As a result, it was found that participants' free time satisfaction levels were related to age; stress levels were related to variables such as age, sport year, national team year, and income level; and there was a significant negative correlation between the FTSS and SSWL.

To conclude, we can say that free-time activities play an important role in elite-level wrestlers, saturation levels are effective in their sport performance, and stress levels change according to various factors. Future studies should also focus on elite-level athletes in other branches, which would allow one to compare different branches.

Author Contributions: All the authors contributed equally to design the study. F.Y. and H.A. gathered data, scanned literature, and prepared the text. The statistical analysis of the research was carried out by I.K. The text was revised and edited by M.T.

Funding: This research received no external funding.

Acknowledgments: The authors wish to thank the participants for their effort and contributions to this study.

Conflicts of Interest: The authors declare no conflict of interest. 


\section{References}

1. Badau, D.; Badau, A. The motric, Educational, Recreational and Satisfaction Impact of Adventure Education Activities in the Urban Tourism Environment. Sustainability 2018, 10, 2106. [CrossRef]

2. Badau, A.; Badau, D.; Serban, C.; Tarcea, M.; Rus, V. Wellness integrative profile 10 (WIP10)—An integrative educational tool of nutrition, fitness and health. J. Pak. Med. Assoc. 2018, 68, 882-887.

3. Armstrong, L.E.; Van Heest, J.L. The unknown mechanism of the overtraining syndrome: Clues from depression and psychoneuroimmunology. Sports Med. 2002, 32, 185-209. [CrossRef] [PubMed]

4. Eskin, M.; Harlak, H.; Demirkiran, F.; Dereboy, C. Adaptation of perceived stress scale to Turkish: Reliability and validity analysis. New Symp. J. 2013, 51, 132-140.

5. Aydin, Y. An Analysis of the Relationship between Adults' Stress Levels and Stress Relief Measures and Attention Deficit Symptoms. Master's Thesis, Toros University Institute of Social Sciences, Mersin, Turkey, 2017.

6. Ryska, T.A.; Yin, Z. Dispositional and situational goal orientations as discriminators among recreational and competitive league athletes. J. Soc. Psychol. 1999, 139, 335-342. [CrossRef] [PubMed]

7. Udry, E.; Gould, D.; Bridges, D.; Tuffey, S. People helping people? Examining the social ties of athletes coping with burnout and injury stress. J. Sport Exerc. Psychol. 1997, 19, 368-395. [CrossRef]

8. $\quad$ Roberts, K. Leisure in Contemporary Society, 2nd ed.; CABI: Wallingford, UK, 2006.

9. Schermerhorn, J.R.; Hunt, J.G.; Osborn, R.N. Management; John Willey and Sons: New York, NY, USA, 1994.

10. Choi, S.; Fu, X. Re-examining the dimensionality of leisure motivation and leisure satisfaction in a multicultural context: Evidence from Macau. Hum. Soc. Sci. Rev. 2015, 3, 6-10.

11. Yerlisu-Lapa, T.; Ardahan, F.; Atay, E. A comparison of leisure satisfaction levels of students from different universities in relation to some variables. Energy Educ. Sci. Technol. Part B Soc. Educ. Stud. 2012, 4, 2559-2566.

12. Beard, J.G.; Ragheb, M.G. Measuring leisure satisfaction. J. Leis. Res. 1980, 12, 20-33. [CrossRef]

13. Yasarturk, F. Examination of Life Satisfaction, Sense of Boredom and Attitude in the Preferences towards Recreational Activities of Elite-Level Athletes. Ph.D. Thesis, Sakarya University Institute of Education Sciences, Sakarya, Turkey, 2016, unpublished.

14. Gokce, H.; Orhan, K. Turkish validity reliability study of free time satisfaction scale. Hacettepe J. Sport Sci. 2011, 22, 139-147.

15. Odabasi, Z. Stress in Working Life. Master's Thesis, Marmara University Social Sciences Institute, Istanbul, Turkey, 2006.

16. Ozdevecioglu, M.; Yalcin, Y. The effect of sports satisfaction on the level of stressors and aggression of sportsmen. Nigde Univ. J. Phys. Educ. Sports Sci. 2010, 4, 63-76.

17. Can, A. Quantitative Data Analysis in Scientific Research Process with Spss, 3rd ed.; Pegem Academy: Ankara, Turkey, 2014.

18. Eraslan, M.; Dunn, B.L. Stress level evaluation of physical education and sports academy students based on various parameters. Nigde Univ. J. Phys. Educ. Sports Sci. 2015, 9, 179-185.

19. Olff, M.; Langeland, W.; Draijer, N.; Gersons, B.P. Gender differences in posttraumatic stress disorder. Psychol. Bull. 2007, 133, 183. [CrossRef] [PubMed]

20. Sonmezoglu, U.; Polat, E.; Aycan, A. Youth center members and free time satisfaction levels according to some variables. Int. J. Sci. Cult. Sport 2014, 1, 219-229. [CrossRef]

21. Akgul, B.M.; Ayyildiz, T.; Karaman, M. Examination of leisure satisfaction levels of individuals participating in recreative activities through sports centers with regard to some variables. Nigde Univ. J. Phys. Educ. Sports Sci. 2014, 8, 278-287.

22. Muzindutsi, F.P. Determinants of leisure satisfaction among undergraduate students at a South African university. Int. J. Bus. Manag. Stud. 2015, 7, 1-15.

23. Ayyildiz, T.; Gokyurek, B. Examination of leisure satisfaction levels of individuals participating in recreative dance activities. Sci. Mov. Health 2016, 16, 147-155.

24. Ayyildiz, T.; Karaman, M.; Yaman, M.; Okan, I. Examination of life satisfaction and leisure satisfaction levels of individuals participating sport actıvities in their leisure time. Online J. Recreat. Sport 2016, 5, 45-60. [CrossRef]

(C) 2018 by the authors. Licensee MDPI, Basel, Switzerland. This article is an open access article distributed under the terms and conditions of the Creative Commons Attribution (CC BY) license (http:/ / creativecommons.org/licenses/by/4.0/). 